\title{
Exploratory Geochemical Studies to Determine the Mineralization Zones Around the Zarshuran Gold Mine
}

\author{
Saeed Heidarlaki \\ Shahrood University of \\ Technology \\ Shahrood, Iran
}

\author{
Mansour Ziaii * \\ Shahrood University of \\ Technology \\ Shahrood, Iran
}

\author{
Peyman Afzal \\ Islamic Azad University \\ Tehran, Iran
}

\author{
Mehdi Ziaei \\ Shahrood University of \\ Technology \\ Shahrood, Iran
}

\begin{abstract}
The study area is located in the northern part of Takab, West Azarbaijan Province, northwest of Iran. Since geochemical explorations, especially the drainage sediments, play a very important role in finding promising areas and providing conditions for more detailed exploration. Detection and separation of geochemical anomalies from the field is one of the most important and fundamental issues in geochemical exploration. In this study, using the classical statistcs methods, anomalous values were determined. Other methods used in this study is the concentration-area (C-A) fractal method. This method is a very successful method for separating anomalies from the field due to simultaneous consideration of the frequency and spatial variations of geochemical data. Multivariate statistical analysis including principal component analysis (PCA) was used to obtain anomaly values related to determine the anomaly values. Favorable results for the methods used for this region was presented.
\end{abstract}

Keywords: PCA; C-A Fractal; Geostatistics; Gold Mineralization; Zarshuran

\section{INTRODUCTION}

The statistics are a vast array of maths that study ways to collect, summarize, and conclude data. This science applies to a wide range of academic sciences from physics and social sciences to anthropology, as well as business, government, and industry. Statistics is the science and practice of human development through the use of experimental data. Statistics are based on the theory of statistics, which is a branch of applied mathematics. In statistical theory, random events and uncertainty are modeled by probability theory. In this science, studying and judging on various subjects is done on the basis of a society and judgment about a particular person is not at all questionable [1] [2].

The geostatistics is the most important statistical theory based on the field concept of the place, is the theory of regional variables. The regional variable is defined as any environment property whose numerical values are distributed in one, two, or three-dimensional sampling space. The spatial variations of a regional variable have two structural and random components. One of the main goals of spatial statistics is to provide an appropriate model for describing the regional variable by taking into account the structural and random variability components. This section of spatial statistics is called geostatistics [3] [2].

Separation of anomalies from the background is one of the most important and key steps in geochemical exploration. There are several ways to identify and separate anomalous areas from the field [4]. Separation of geochemical anomalies from background has always been a major concern of exploration geochemistry[5]. The search for methods that can make this analysis quantitative and objective aims not only at the reduction of subjectiveness but also at providing an automatic routine in exploration, assisting the interpretation and production of geochemical maps [6].

Geochemical explorations are the basis for the mineral processing studies. Therefore, in exploration, the economy and the processing capabilities should always be easy and cost-effective [7]. In determining the zones of alteration and mineralization in the area, remote sensing methods help a lot, in addition to giving us a large view of the mineralization process in the region. Therefore, if remote sensing and geochemical studies are combined, mineralization can be accurately determined [8] [9].

\section{Methodology and Dataset 2.1. Geolocation and Sampling}

The Zarshuran mineral zone is located in West Azarbaijan province of Iran and on geological sheet of Takht-e-Soleyman (on sclae 1:100,000). The Takht-e-Soleyman sheet covers parts of Zanjan, West Azarbaijan and East Azarbaijan provinces. The Takht-e-Soleyman sheet is part of the 1: 250000 geological map of the Takab rectangle between the eastern longitude $47^{\circ} 00^{\prime}$ and $47^{\circ} 30^{\prime}$ and the north latitude $36^{\circ} 30^{\prime}$ 'to $37^{\circ} 00^{\prime}$. The quadrilateral coordinates of the studied area are presented in Table 1. Due to its location in the Takab metallurgical province and the location of the AlborzAzarbaijan, Iran Central and Sanandaj-Sirjan construction zones, this area has a lot of mineralization diversity. The most important mineralization in this area is the lead and zinc mineralization (Anguran, Alam Kandy and Arpachai) and gold mineralization (Zarshuran, Aghdare and Tozlar). The study area of this project is located between Zanjan and East Azarbaijan provinces around the Zarshuran gold mine. Geolocation of study area in Iran map is shown in figure 1 . 
Table 1. Geographical coordinates of study area

\begin{tabular}{|c|c|c|}
\hline \multicolumn{2}{|c|}{ Geographical Coordinates } & \\
\hline Latitude (Y) & Longitude $(\mathbf{X})$ & \\
\hline $36^{\circ} 40^{\prime} 49^{\prime \prime}$ & $47^{\circ} 08^{\prime} 00^{\prime \prime}$ & $\mathbf{A}$ \\
\hline $36^{\circ} 44^{\prime} 06^{\prime \prime}$ & $47^{\circ} 08^{\prime} 00^{\prime \prime}$ & $\mathbf{B}$ \\
\hline $36^{\circ} 44^{\prime} 06^{\prime \prime}$ & $47^{\circ} 12^{\prime} 03^{\prime \prime}$ & $\mathbf{C}$ \\
\hline $36^{\circ} 40^{\prime} 49^{\prime \prime}$ & $47^{\circ} 12^{\prime} 03^{\prime \prime}$ & D \\
\hline
\end{tabular}

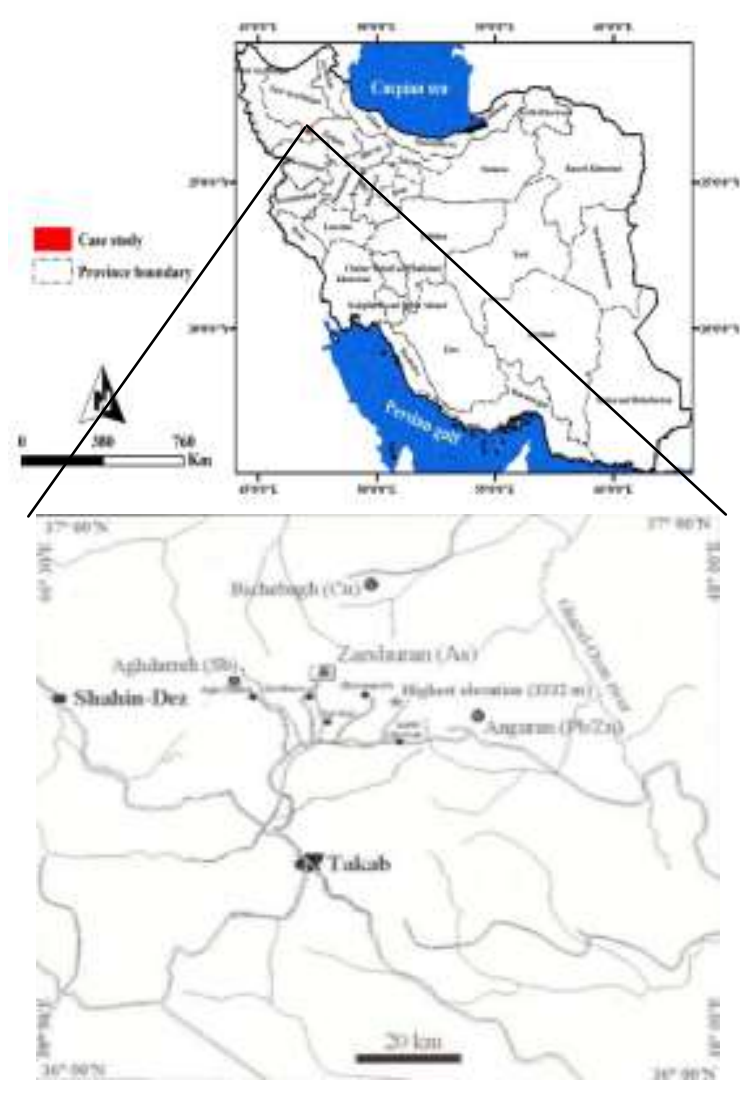

Figure 1. Geolocation of study area in Iran map

In the study area, 72 geochemical samples were taken from the drainage sediments. The position map of the 72 drainage sediments samples taken from the study area is shown in Figure 2.

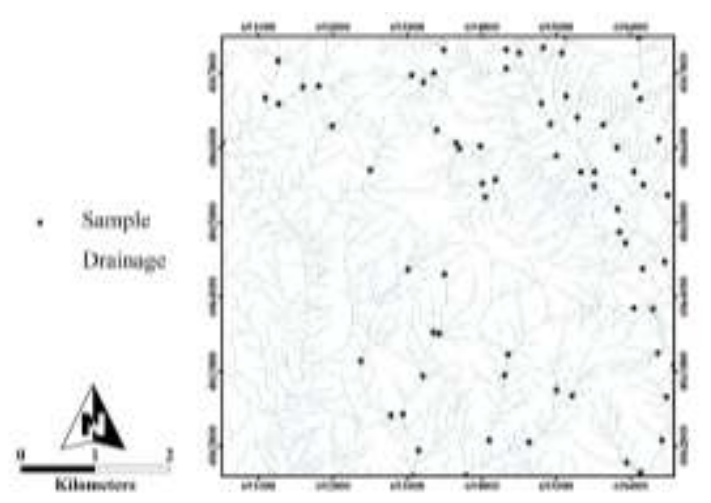

Figure 2. Position of drainage sediments samples taken from the study area.

\subsection{Correlation Analysis}

Correlation is used to test relationships between quantitative variables or categorical variables. In other words, it's a measure of how things are related. The study of how variables are correlated is called correlation analysis [10]. Correlations are useful because if you can find out what relationship variables have, you can make predictions about future behavior [11]. Correlation analysis in geochemical data is very important. One of the valuable results of the investigation of the correlation between chemical elements is the identification of the mineralization and geochemical behavior of the region [12] [2].

\subsection{Hierarchical Clustering}

In data mining and statistics, hierarchical clustering (also called hierarchical cluster analysis or HCA) is a method of cluster analysis which seeks to build a hierarchy of clusters. Strategies for hierarchical clustering generally fall into two types [13]:

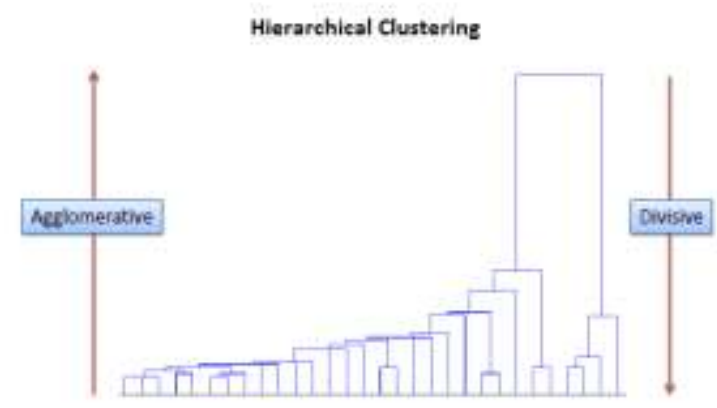

Figure 3. hierarchical clustering strategies

- Agglomerative Method:

This is a "bottom up" approach: each observation starts in its own cluster, and pairs of clusters are merged as one moves up the hierarchy.

\section{- Divisive Method:}

This is a "top down" approach: all observations start in one cluster, and splits are performed recursively as one moves down the hierarchy (see figure 3 ).

\subsection{Principal Components Analysis (PCA)}

Principal component analysis (PCA) is a statistical procedure that uses an orthogonal transformation to convert a set of observations of possibly correlated variables into a set of values of linearly uncorrelated variables called principal components. Principal Component Analysis (PCA) is the general name for a technique which uses sophisticated underlying mathematical principles to transforms a number of possibly correlated variables into a smaller number of variables called principal components. The origins of PCA lie in multivariate data analysis, however, it has a wide range of other applications, as we will show in due course. PCA has 
been called, 'one of the most important results from applied linear algebra and perhaps its most common use is as the first step in trying to analyse large data sets. Some of the other common applications include; de-noising signals, blind source separation, and data compression [14] [15].

In general terms, PCA uses a vector space transform to reduce the dimensionality of large data sets. Using mathematical projection, the original data set, which may have involved many variables, can often be interpreted in just a few variables (the principal components). It is therefore often the case that an examination of the reduced dimension data set will allow the the user to spot trends, patterns and outliers in the data, far more easily than would have been possible without performing the principal component analysis. The aim of this essay is to explain the theoretical side of PCA, and to provide examples of its application. We will begin with a nonrigorous motivational example from multivariate data analysis in which we will attempt to extract some meaning from a 17 dimensional data set. After this motivational example, we shall discuss the PCA technique in terms of its linear algebra fundamentals. This will lead us to a method for implementing PCA for real-world data, and we will see that there is a close connection between PCA and the singular value decomposition (SVD) from numerical linear algebra. We will then look at two further examples of PCA in practice; Image Compression and Blind Source Separation [16] [17].

\subsection{Concentration-Area (C-A) Fractal}

Ever since Mandelbrot $(1974,1972)$ introduced the concept offractals in the last century [18], fractal or multi-fractal analysis hasquickly developed into an important branch of non-linear scienceand has had significant impacts in many areas of natural sciencesto characterize self-similar or selfaffine measures [19]. The C-A method serves to illustrate the relationship between theobtained results and the geological, geochemical and mineralogicalinformation. Its most useful features are the easy implementa-tion and the ability to compute quantitative anomalous thresholds. Cheng et al. (1994) proposed an element concentration-area (C-A) model, which may be used to define the geochemical backgroundand anomalies. The model has the general form of Eq. following [20] [21]:

$$
(\rho \leq v) \propto \rho^{-a_{1}} ; \quad A(\rho \leq v) \propto \rho^{-a_{2}}
$$

Where $A(\rho)$ denotes the area with concentration values greaterthan the contour value $\rho$; v represents the threshold; and a1and a2are characteristic exponents. Using the fractal theory, Cheng et al.(1994) derived similar power-law relationships and equations inextended form. The two approaches which were used to calculate $A(\rho)$ by Cheng et al. (1994) were (1) the $A(\rho)$ is the area enclosedby contour level q on a geochemical contour map resulting frominterpolation of the original data using a weighted moving aver-age method, and (2) $A(\rho)$ are the values obtained by boxcountingof the original elemental concentration values. By box-counting,one superimposes a grid with cells on the study region. The area $A(\rho)$ for a given $\mathrm{q}$ is equal to the number of cells multiplied by thecell area with concentration values greater than $\rho$. Average concen-tration values are used for those boxes containing more than onesample. Area $\rho$ concentration $[A(\rho)]$ with element concentrationsgreater than $\rho$ usually shows a power-law relation [22] [23]. The breaks betweenstraight-line segments on this plot and the corresponding values of _ have been used as cut-offs to separate geochemical values intodifferent components, representing different causal factors, suchas lithological differences and geochemical processes. Factors suchas mineralizing events, surface geochemical element concentra-tions, and surface weathering are of considerable importance [24]. The multi-fractal theory may be interpreted as a theo-retical framework that explains the power-law relations betweenareas enclosing concentrations below a given value and the actualconcentrations.

\section{Results and Discussion}

\subsection{Correlation Analysis}

In Table 2, the correlation coefficients of elements are derived from the Spearman method. Therefore, in this project, the basis for interpreting the relations between different elements is Spearman's nonparametric correlation test. According to the two-variable Spearman test, the following results can be presented:

- Pearson correlation coefficient between 0.230 and 0.230 and Spearman between 0.231 and -0.231 at 95\% confidence level are invalid and meaningless. This value is at the confidence level of $99 \%$ for Pearson correlation coefficients and Spearman between 0.300 and -0.300 .

- Au with As, $\mathrm{Cd}, \mathrm{Sb}$ and $\mathrm{Zn}$ correlations show a significant and moderate to high correlation.

- Ag only has a significant and moderate correlation with $\mathrm{Zn}$.

- $\quad \mathrm{As}, \mathrm{Cd}, \mathrm{Cu}, \mathrm{S}, \mathrm{Sb}$ and $\mathrm{Zn}$ have a positive and significant correlation with each other and can therefore be considered as a tracer or associated with mineralization.

- There is a positive and significant correlation between elements such as $\mathrm{Al}, \mathrm{Ba}, \mathrm{Be}, \mathrm{Ca}, \mathrm{Ce}, \mathrm{Cu}$, $\mathrm{K}, \mathrm{La}, \mathrm{Li}, \mathrm{Mo}, \mathrm{Na}, \mathrm{P}, \mathrm{Pb}, \mathrm{Sr}, \mathrm{Th}, \mathrm{Ti}, \mathrm{U}, \mathrm{Y}, \mathrm{Yb}$ and $\mathrm{Zr}$. There is a medium to large. This correlation is undoubtedly influenced by the surrounding stones.

- There is a significant correlation between $\mathrm{Au}, \mathrm{Cr}$, $\mathrm{Co}, \mathrm{Fe}, \mathrm{Mg}, \mathrm{Mn}, \mathrm{Ni}, \mathrm{Sb}$ and $\mathrm{Zn}$. The group also describes the chemistry of the rocky outcrops of the region, which are considered to be mafic as compared to the elements of the preceding clause. 
Table 2. Calculation of correlation coefficients of elements using Pearson method for normalized geochemical data

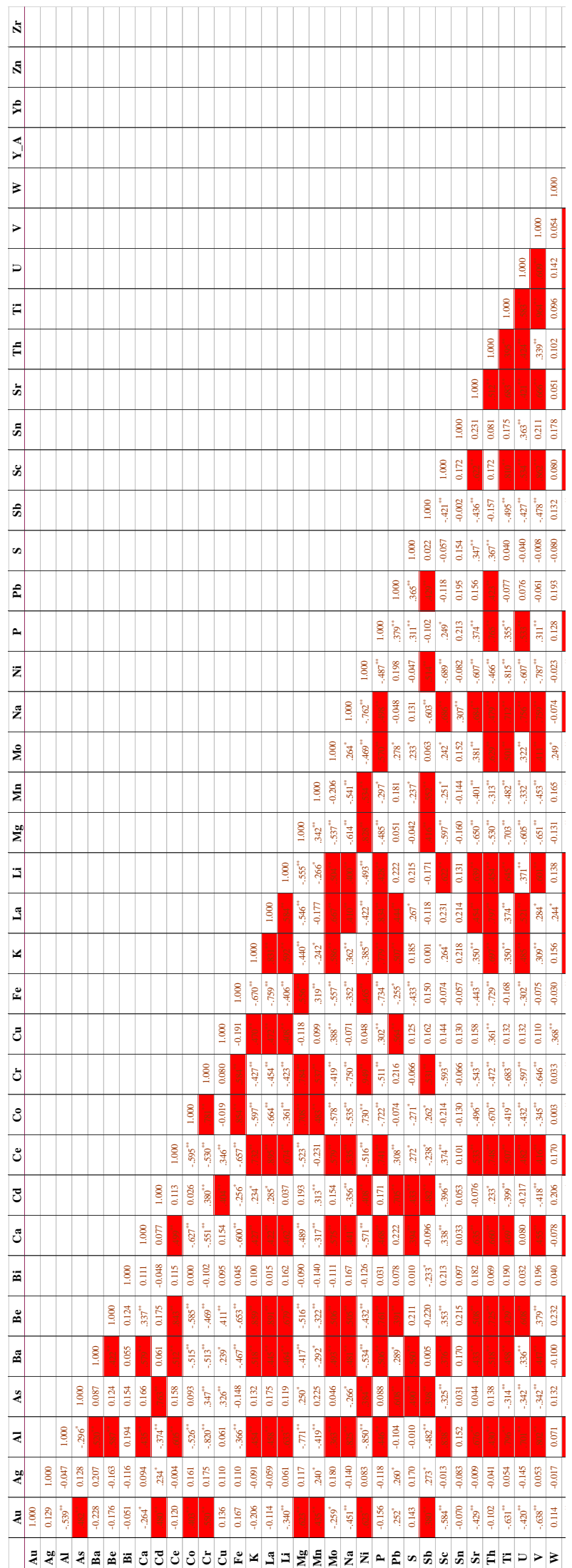

\subsection{Hierarchical Clustering}

Figure 4 shows the Hierarchical Clustering chart for cluster analysis of normal data. According to this diagram, the following results can be obtained :

- The resulting chart has two main clusters. Each of these clusters is divided into two sub-clusters.

- The lower cluster is not explicitly exploratory, and due to the correlation of elements of this cluster, it is anticipated that these elements are related to the chemistry of surface rocks in the region.

- The upper cluster itself is divided into two subbranches or branches, each of which in turn has smaller subdivisions. Meanwhile, confirmation of the correlation between the elements $\mathrm{Ag}, \mathrm{As}, \mathrm{Au}$, $\mathrm{Cd}, \mathrm{Cu}, \mathrm{Mn}, \mathrm{Pb}, \mathrm{S}, \mathrm{Sb}$ and $\mathrm{Zn}$ is the most important finding of this graph.

- The three Bi, Sn, and W elements form a sub branch of the upper branch. These elements are notable in this exploratory area. However, the combination of these elements with elements of $\mathrm{Ag}, \mathrm{As}, \mathrm{Au}, \mathrm{Cd}$, $\mathrm{Cu}, \mathrm{Mn}, \mathrm{Pb}, \mathrm{S}, \mathrm{Sb}$ and $\mathrm{Zn}$ elements can be of great importance from the genetic point of view.

- Another major branch of the upper branch is the Co, $\mathrm{Cr}, \mathrm{Fe}, \mathrm{Mg}$ and Ni elements. The existence of such a correlation was also detectable in a bivariate test. Therefore, it can be used in genetic topics.

- Finally, according to the analyzes carried out at the earlier stages among all the elements, 14 important elements were detected that included $\mathrm{Au}, \mathrm{Ag}, \mathrm{As}$, $\mathrm{Cd}, \mathrm{Co}, \mathrm{Cr}, \mathrm{Cu}, \mathrm{Mn}, \mathrm{Mo}, \mathrm{Ni}, \mathrm{Pb}, \mathrm{Sb}, \mathrm{W}$ and $\mathrm{Zn}$ and were selected by main component analysis method (PCA).

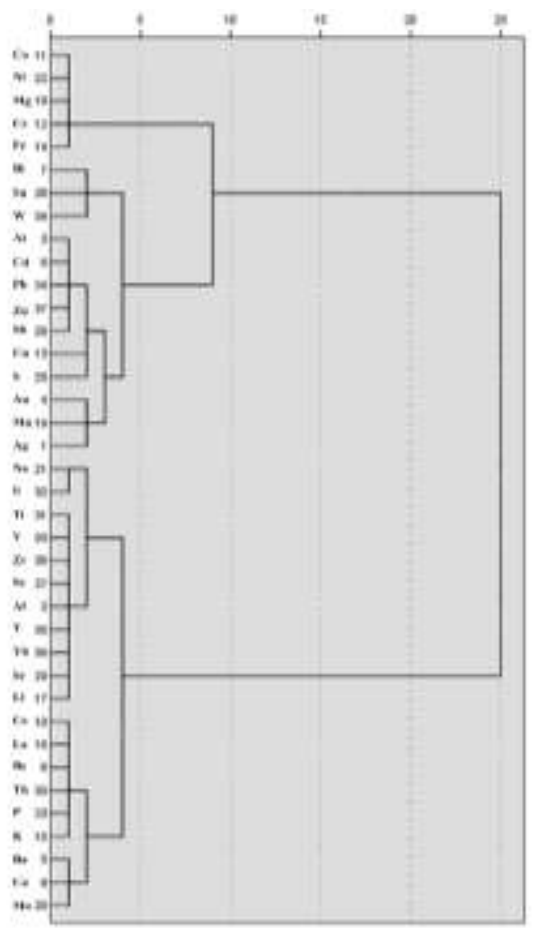

Figure 4. Logarithmic Dendrogram for Ward Method. 


\subsection{Principal Components Analysis (PCA)}

According to the Scree Plot chart (Figure 5), there are 14 total factors, of which only 3 first factors have been selected due to special values above 1 as effective factors.

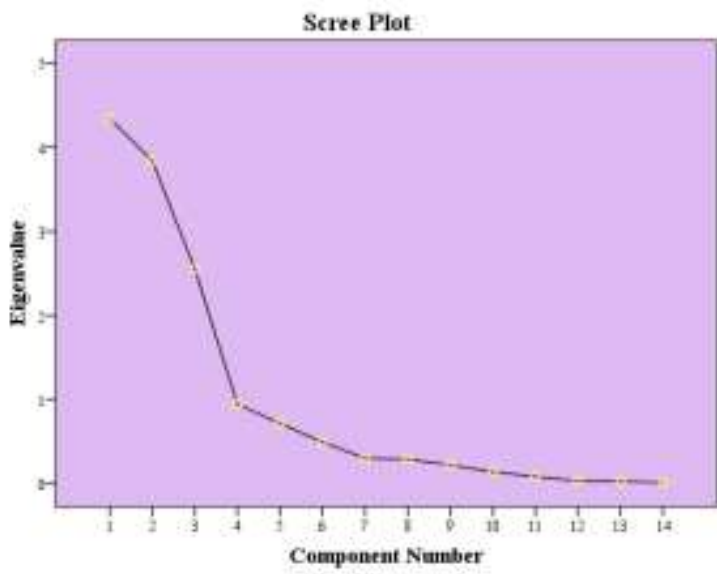

Figure 5. Scree plot derived from the results of the factor analysis of the 14 selected normal elements.

The PCA results are characterized by three main components. According to Table 3, all three main components have special values greater than 1 . The value of the variance for each component indicates the degree of variability of the data in that particular component.

Table 3. The results of the main components analysis (PCA) for the 14 selected elements.

\begin{tabular}{|c|c|c|c|}
\hline Elements & PC1 & PC2 & PC3 \\
\hline Au & 0.450 & 0.094 & $\mathbf{0 . 5 2 4}$ \\
\hline $\mathbf{A g}$ & 0.052 & 0.016 & $\mathbf{0 . 5 3 3}$ \\
\hline $\mathbf{A s}$ & 0.149 & -0.091 & $\mathbf{0 . 8 2 0}$ \\
\hline Cd & 0.000 & $\mathbf{0 . 8 1 9}$ & $\mathbf{0 . 4 7 5}$ \\
\hline Co & $\mathbf{0 . 9 6 0}$ & -0.162 & 0.049 \\
\hline Cr & $\mathbf{0 . 9 4 4}$ & 0.098 & 0.175 \\
\hline Cu & -0.157 & $\mathbf{0 . 5 0 5}$ & $\mathbf{0 . 5 2 1}$ \\
\hline Mn & 0.181 & $\mathbf{0 . 9 2 3}$ & 0.007 \\
\hline Mo & -0.723 & 0.317 & 0.367 \\
\hline Ni & $\mathbf{0 . 9 5 8}$ & 0.175 & 0.110 \\
\hline Pb & -0.103 & 0.316 & $\mathbf{0 . 7 5 4}$ \\
\hline Sb & -0.037 & $\mathbf{0 . 5 5 0}$ & $\mathbf{0 . 6 4 2}$ \\
\hline W & -0.104 & $\mathbf{0 . 9 5 5}$ & -0.212 \\
\hline Zn & 0.188 & -0.532 & $\mathbf{0 . 7 7 6}$ \\
\hline Var. & 26.03 & 25.43 & 25.25 \\
\hline
\end{tabular}

\subsection{Distribution of elements concentration}

At this stage, the values of the 8 selected elements of importance identified in the previous sections were used to represent the distribution of various elements in the study area. They were interpolated using the IDW method (weighted by inverted distance) in the Arc GIS 10.2 environment.
To map geochemical information in the software environment, an appropriate size is chosen for the size of the pixels for interpolation. In this step, in order to find the appropriate size for the size of the pixels for interpolation, according to Hengl [25] the following formula is used:

$$
x=\sqrt{\frac{A}{n}} \times 0.05
$$

In this formula, $\mathrm{x}$ is the appropriate cell size, $\mathrm{A}$ is the area of the study area in $\mathrm{m}^{2}$, and $\mathrm{n}$ is the number of samples taken from the range. Here, $A=6 * 6$ and $n=72$, which after reaching the formula above is $\mathrm{x}=0.03 \mathrm{~m}^{2}$, after which all interpolations made with cell size will be 0.03 square meters.

Subsequently, using the inverse distance weighing method (IDW), 8 elements including $\mathrm{Ag}, \mathrm{As}, \mathrm{Au}, \mathrm{Cd}, \mathrm{Cu}, \mathrm{Pb}, \mathrm{Sb}$ and $\mathrm{Zn}$ were continuously interpolated and the distribution maps of the geochemical anomalies related to these elements in figure 6 to 13 are visible. According to the studies carried out in the previous section, according to the main components analysis method, based on the points allocated to each of the samples under the third component (PC3), the final map of the geochemical anomaly is also drawn (Figure 4-14).

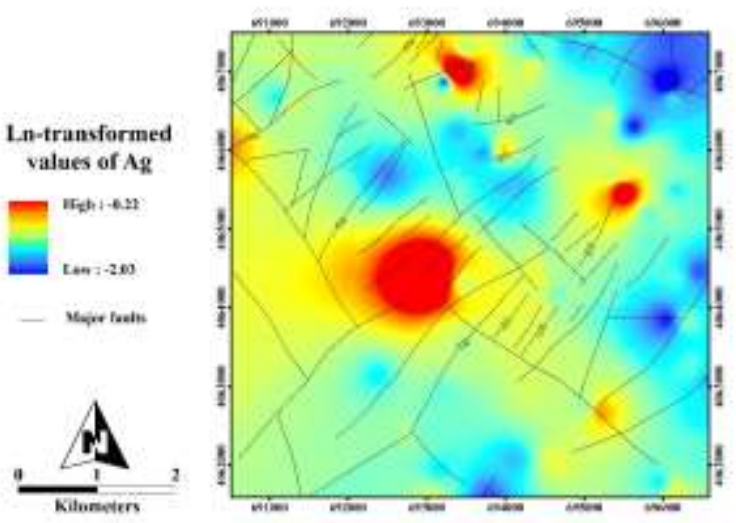

Figure 6. Distribution map of geochemical anomalies for Ag element.

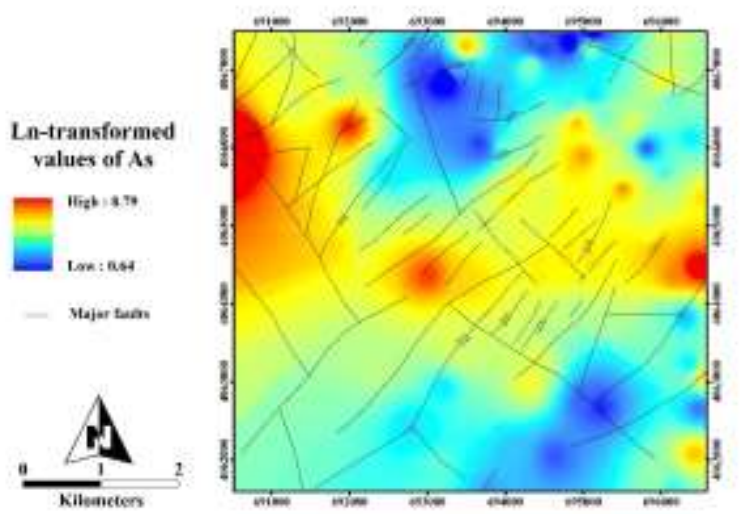

Figure 7. Distribution map of geochemical anomalies for As element. 


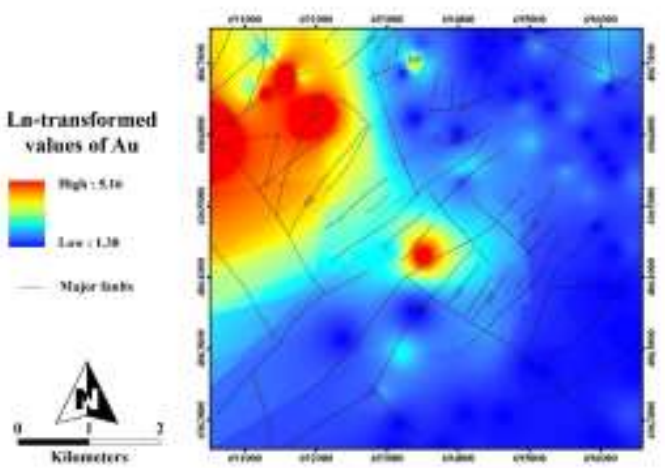

Figure 8. Distribution map of geochemical anomalies for Au element.

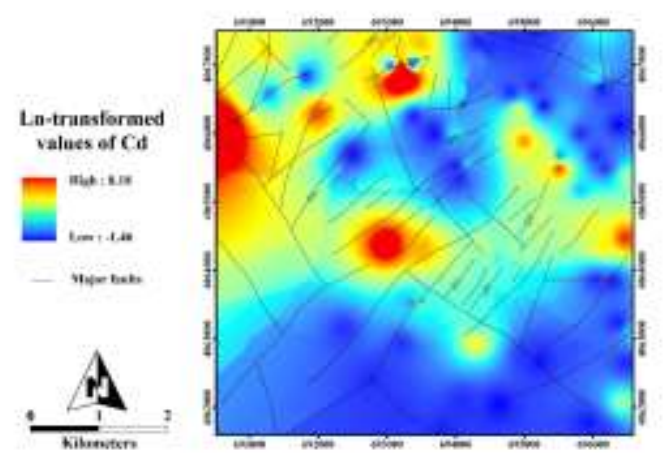

Figure 9. Distribution map of geochemical anomalies for Cd element.

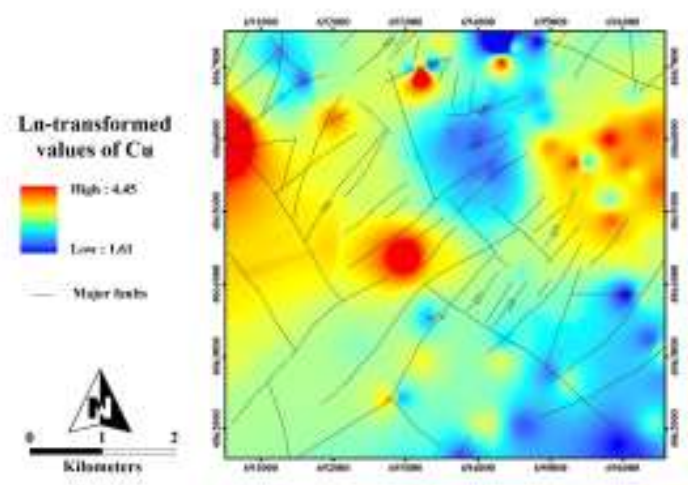

Figure 10. Distribution map of geochemical anomalies for Cu element.

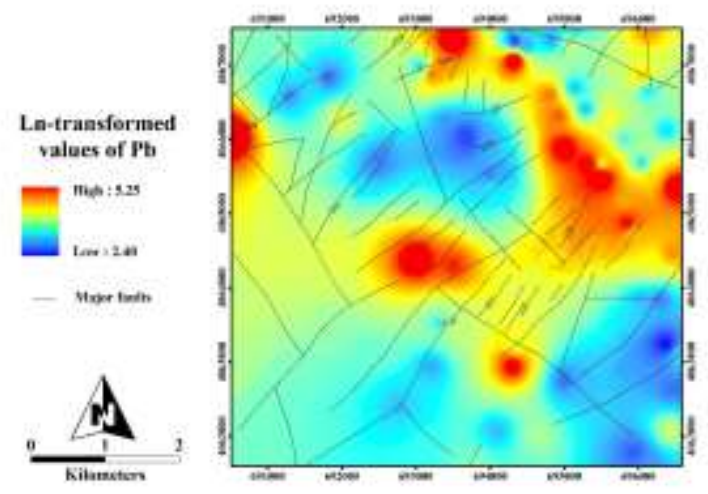

Figure 11. Distribution map of geochemical anomalies for Pb element.

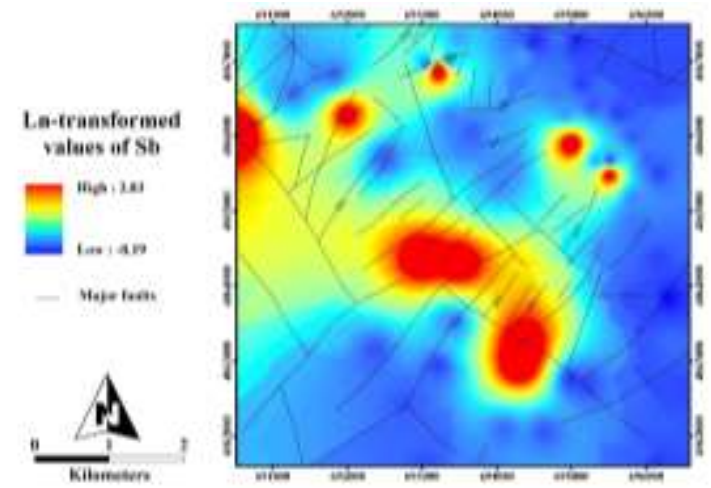

Figure 12. Distribution map of geochemical anomalies for Sb element.

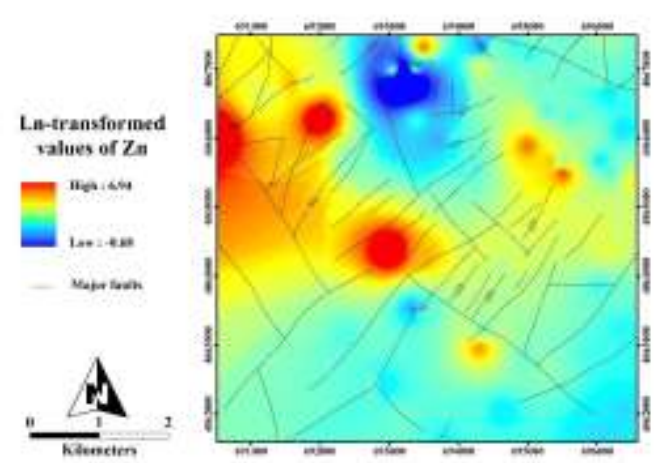

Figure 13. Distribution map of geochemical anomalies for Zn element.

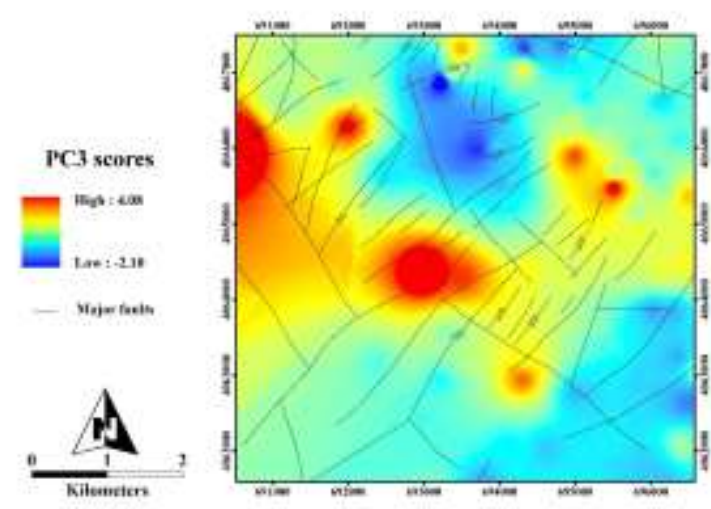

Figure 14. Distribution Map of Geochemical Anomalies for the Scores derived from the Third Component Analysis of Principal Components.

\subsection{Estimated threshold}

Firstly, eight elements were selected first for single-element geochemical data fractal modeling. For the fractal modeling by concentration-area method, the distribution of the 8 elements of the above mentioned elements, as described in the previous sections, was first normalized using logarithmic transformation, then ArcGIS 10.2 software was interpolated using the IDW method and mapped. Then, using the initial maps, the cumulative area of the pixels was calculated for definite grades, and the graphs plotted against the area were plotted in full logarithm. In order to determine the different 
communities, direct lines were fitted on the points of the diagram based on the least squares law, and on the basis of which the thresholds and the number of different geochemical communities were determined.

It should be noted that the number of thresholds from the number of geochemical communities is always one unit less. In Figure 15, the Fractal Characteristics of the Gradient-Area Fractures for the 8 elements, $\mathrm{As}, \mathrm{Au}, \mathrm{Cd}, \mathrm{Cu}, \mathrm{Pb}, \mathrm{Sb}$ and $\mathrm{Zn}$ are shown with the threshold lines.
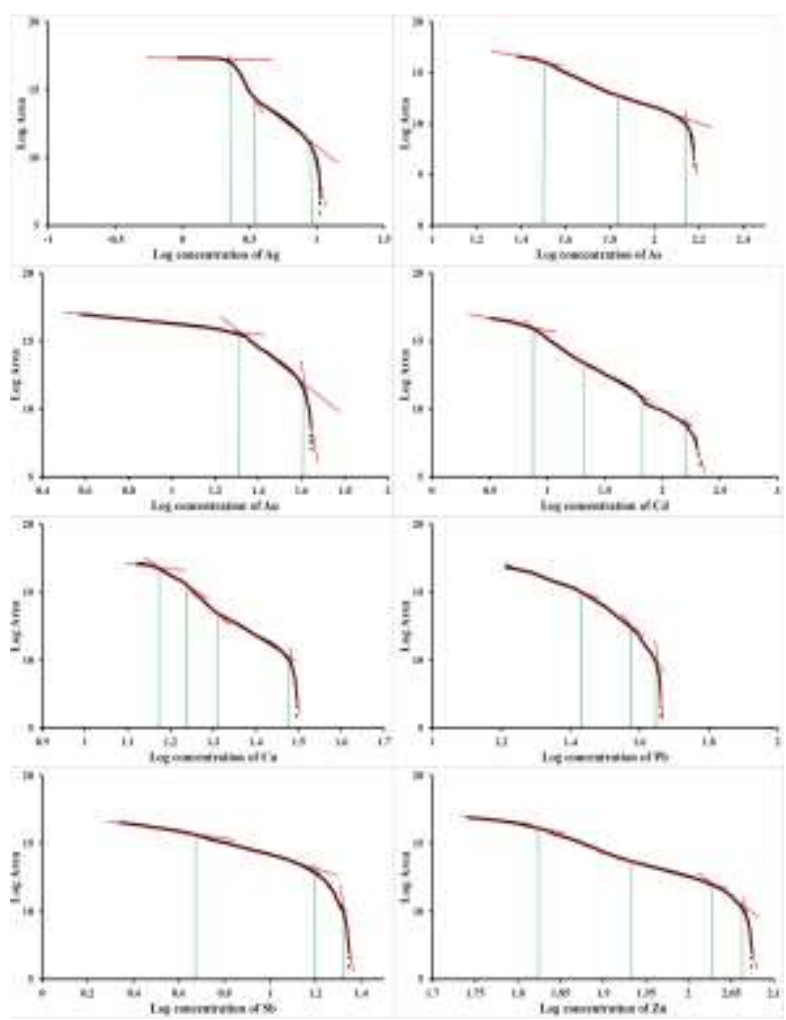

Figure 15. full-logarithmic graphs of concentration-area for the elements

After plotting full-logarithmic graphs for the elements studied and determining the thresholds and different geochemical communities, using the thresholds obtained from the diagram, from the existing data set, the value of the equivalent of each threshold limit (Table 4) and the final anomaly map classified using a full-gravity fractal method.

Figure 16 illustrates anomaly maps classified for the eight elements using the full-size fractal method. As is clear from the figure, geochemical communities are distinguished for different elements and can be used for more detailed studies on the region and for the discovery of new anomalies and for finding promising areas.

\subsection{C-A fractal modeling of the values of PCA Values}

The PC3 privileges were logged into Arc GIS 10.2 software and were internalized by the IDW method. Then all logarithmic graphs of values were plotted against the area occupied by those values (Figure 17). According to the entire logarithmic diagram of the concentration-area, four geochemical societies are identified and segregated based on the lines fitted on the chart based on the least squares method. These societies are composed of fields, low anomalies, moderate anomalies and strong anomalies, respectively.

Then, the estimated thresholds were entered into the software and the final map of the geochemical anomaly modeling for gold mineralization in Zarshuran range was obtained by the concentration-area fractal method, which provided low, medium and strong anomaly values for exploration and investigation More precise in the studied area can be used. The community with a moderate anomaly in identifying promising areas can be a good exploratory guide, and communities with strong anomaly values can also be used in more detailed exploration areas (Figure 18).

Table 4. The thresholds obtained for each selected element

\begin{tabular}{|c|c|c|c|}
\hline Element & Population & Thresho & (ppm) \\
\hline & 1 & 0.13 & 0.20 \\
\hline Ag & 2 & 0.20 & 0.27 \\
\hline & 3 & 0.27 & 0.66 \\
\hline & 4 & 0.66 & 0.80 \\
\hline & 1 & 1.90 & 107.13 \\
\hline As & 2 & 107.13 & 578.36 \\
\hline & 3 & 578.36 & 4713.75 \\
\hline & 4 & 4713.75 & 6576.82 \\
\hline & 1 & 4 & 40.2 \\
\hline Au (ppb) & 2 & 40.2 & 146.7 \\
\hline & 3 & 146.7 & 174.9 \\
\hline & 1 & 0.23 & 1.45 \\
\hline & 2 & 1.45 & 5.66 \\
\hline Cd & 3 & 5.66 & 71.80 \\
\hline & 4 & 71.80 & 951.71 \\
\hline & 5 & 951.71 & 3588.23 \\
\hline & 1 & 5 & 24.96 \\
\hline & 2 & 24.96 & 31.15 \\
\hline $\mathbf{C u}$ & 3 & 31.15 & 41.54 \\
\hline & 4 & 41.54 & 78.90 \\
\hline & 5 & 78.90 & 85.97 \\
\hline & 1 & 11.03 & 66.24 \\
\hline & 2 & 66.24 & 128.35 \\
\hline $\mathbf{P b}$ & 3 & 128.35 & 178.26 \\
\hline & 4 & 178.26 & 191.89 \\
\hline & 1 & 0.82 & 2.61 \\
\hline Sb & 2 & 2.61 & 10.02 \\
\hline & 3 & 10.02 & 15.39 \\
\hline & $\mathbf{1}$ & 0.50 & 178.34 \\
\hline & 2 & 178.34 & 373.96 \\
\hline $\mathbf{Z n}$ & 3 & 373.96 & 750.97 \\
\hline & 4 & 750.97 & 946.29 \\
\hline & & 964.29 & 1038.28 \\
\hline
\end{tabular}




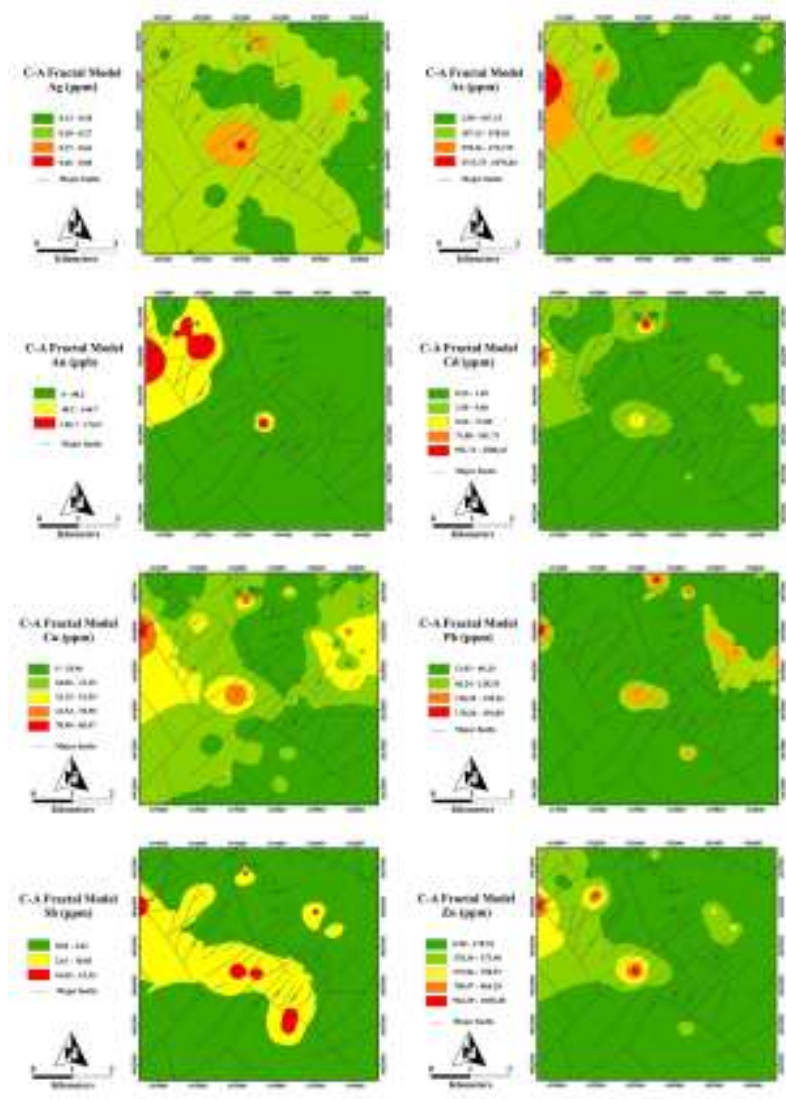

Figure 16. Distribution maps of geochemical communities using concentration-area fractal method for elements.

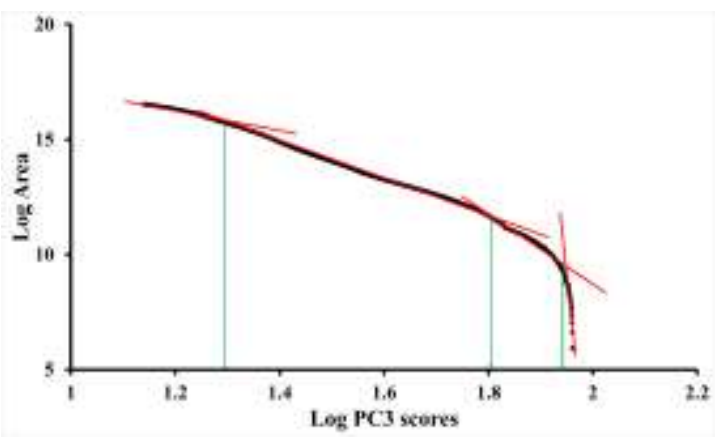

Figure 17: Full-logarithmic plot of concentration-area fractals for values obtained from PC3.

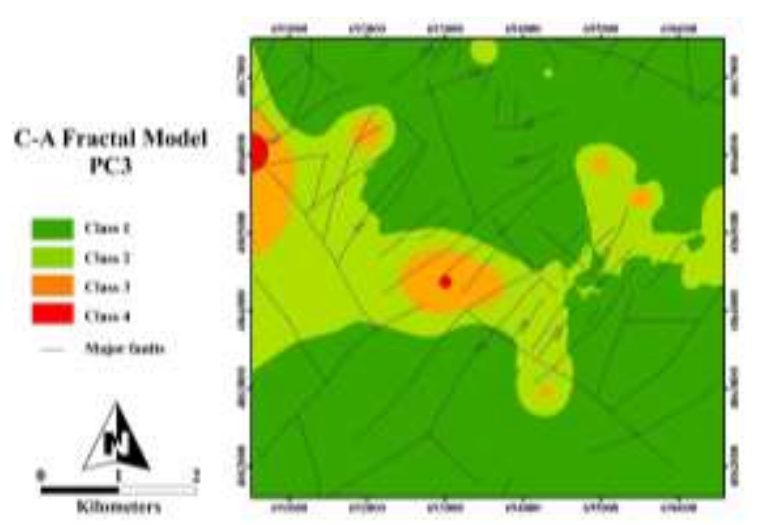

Figure 18. Final map of distribution of geochemical communities for $\mathrm{PC} 3$ values using concentration-area fractal method.

\section{Conclusion}

- To study the potential of gold mineralization in the Zarshuran area, field separation from anomalies such as fractal-geometric methods including concentration-area was used to separate the anomalous areas from the field and identify the geochemical promising areas.

- In this study, all 38 elements were first studied as monovalent and each geochemical pattern was detected. Then, based on the two-variable analysis of geochemical elements, using the coefficients of correlation and principal components analysis, the main values of the third component, as well as the 8 elements including $\mathrm{Ag}, \mathrm{As}, \mathrm{Au}, \mathrm{Cd}, \mathrm{Cu}, \mathrm{Pb}, \mathrm{Sb}$ and $\mathrm{Zn}$, which are most related to mineral The gold mining of the Zarshuran range was selected and used to identify and isolate geochemical patterns.

- In the next step, 8 elements of the method based on the concentration-area fractal geometry were used to separate the anomal area from the background. Based on full logarithmic diagrams, concentrationarea fractal method, 4 enrichment steps for $\mathrm{Ag}$, As and $\mathrm{Pb}$ elements, 5 enrichment steps for $\mathrm{Cu}$ and $\mathrm{Cd}$ elements, 3 enrichment steps for $\mathrm{Au}$ and $\mathrm{Sb}$ elements were obtained. As in the geochemical anomaly maps derived from full-gravity fractal methods, the elements in the central, northeastern and northwest of the Zarshuran range have highlevel anomalies.

- In the next step, by using the principal component analysis method, in the form of a multi-element geochemical map for the identification of gold mineralization, they are combined and for separating the anomaly of the communities from the field for continuous quantities obtained from the method of analysis of the main components of the concentration fractal method -The area was used.

- Based on the full logarithmic graphs of the concentration-area fractal method, 4 different geochemical societies including background, weak anomalies, modal anomalies and strong anomalies were obtained, which shows the high resolution of these methods for identifying areas with potential potential for exploration in this area. 


\section{References :}

[1] Dodge, Y. (2006). The Oxford dictionary of statistical terms: Oxford University Press on Demand.

[2] Alahgholi, S., Shirazy, A., \& Shirazi, A. (2018). Geostatistical Studies and Anomalous Elements Detection, Bardaskan Area, IRAN. Open Journal of Geology, 8(07), 697.

[3] Webster, R., \& Oliver, M. A. (2007). Geostatistics for environmental scientists: John Wiley \& Sons.

[4] Shirazi, A., Hezarkhani, A., Shirazy, A., \& Shahrood, I. (2018). Exploration Geochemistry Data-Application for Cu Anomaly Separation Based On Classical and Modern Statistical Methods in South Khorasan, Iran. International Journal of Science and Engineering Applications, 7, 39-44.

[5] Shirazi, A., Shirazy, A., Saki, S., \& Hezarkhani, A. (2018). Geostatistics Studies and Geochemical Modeling Based on Core Data, Sheytoor Iron Deposit, Iran. Journal of Geological Resource and Engineering, 6, 124-133.

[6] de Mulder, E. F., Cheng, Q., Agterberg, F., \& Goncalves, M. (2016). New and game-changing developments in geochemical exploration. Episodes, 39(1), 70-71.

[7] Khakmardan, S., Shirazi, A., Shirazy, A., \& Hosseingholi, H. (2018). Copper Oxide Ore Leaching Ability and Cementation Behavior, Mesgaran Deposit in IRAN. Open Journal of Geology, 8(09), 841.

[8] Shirazi, A., Hezarkhani, A., Shirazy, A., \& Shahrood, I. (2018). Remote Sensing Studies for Mapping of Iron Oxide Regions, South of Kerman, IRAN. International Journal of Science and Engineering Applications, 7(4), 45-51.

[9] Shirazi, A., Shirazy, A., \& Karami, J. (2018). Remote Sensing to Identify Copper Alterations and Promising Regions, Sarbishe, South Khorasan, Iran. International Journal of Geology and Earth Sciences, 4(2), 36-52.

[10] Chatfield, C. (2018). Introduction to multivariate analysis: Routledge.

[11] Mertler, C. A., \& Reinhart, R. V. (2016). Advanced and multivariate statistical methods: Practical application and interpretation: Taylor \& Francis.

[12] Rollinson, H. R. (2014). Using geochemical data: evaluation, presentation, interpretation: Routledge.

[13] Rokach, L., \& Maimon, O. (2005). Clustering methods Data mining and knowledge discovery handbook (pp. 321-352): Springer.

[14] Manuel, R., Brito, M. d. G., Chichorro, M., \& Rosa, C. (2017). Remote Sensing for Mineral Exploration in Central Portugal. Minerals, 7(10), 184.

[15] Wang, G., Du, W., \& Carranza, E. J. M. (2017). Remote sensing and GIS prospectivity mapping for magmatichydrothermal base-and precious-metal deposits in the Honghai district, China. Journal of African Earth Sciences, 128, 97-115.

[16] Richardson, M. (2009). Principal component analysis. URL: http://people. maths. ox. ac. uk/richardsonm/SignalProcPCA. pdf (last access: 3.5. 2013). Aleš Hladnik Dr., Ass. Prof., Chair of Information and Graphic Arts Technology, Faculty of Natural Sciences and Engineering, University of Ljubljana, Slovenia ales.hladnik@ntf.uni-lj.si, 6, 16.

[17] Jolliffe, I. (2011). Principal component analysis International encyclopedia of statistical science (pp. 1094-1096): Springer.

[18] Mandelbrot, B. B. (1974). Intermittent turbulence in self-similar cascades: divergence of high moments and dimension of the carrier. Journal of Fluid Mechanics, 62(2), 331-358.

[19] Davis, A., Lovejoy, S., \& Schertzer, D. (1991). Radiative transfer in multifractal clouds Non-Linear Variability in Geophysics (pp. 303-318): Springer.

[20] Mohammadi, N. M., Hezarkhani, A., \& Saljooghi, B. S. (2016). Separation of a geochemical anomaly from background by fractal and U-statistic methods, a case study: Khooni district, Central Iran. Chemie der ErdeGeochemistry, 76(4), 491-499.

[21] Cheng, Q., Agterberg, F., \& Ballantyne, S. (1994). The separation of geochemical anomalies from background by fractal methods. Journal of Geochemical Exploration, 51(2), 109-130.

[22] Pazand, K., Hezarkhani, A., Ataei, M., \& Ghanbari, Y. (2011). Application of multifractal modeling technique in systematic geochemical stream sediment survey to identify copper anomalies: a case study from Ahar, Azarbaijan, Northwest Iran. Chemie der Erde-Geochemistry, 71(4), 397-402.

[23] Afzal, P., Harati, H., Alghalandis, Y. F., \& Yasrebi, A. B. (2013). Application of spectrum-area fractal model to identify of geochemical anomalies based on soil data in Kahang porphyry-type Cu deposit, Iran. Chemie der Erde-Geochemistry, 73(4), 533-543.

[24] Lima, A., De Vivo, B., Cicchella, D., Cortini, M., \& Albanese, S. (2003). Multifractal IDW interpolation and fractal filtering method in environmental studies: an application on regional stream sediments of (Italy), Campania region. Applied Geochemistry, 18(12), 1853-1865.

[25] Hengl, T. (2006). Finding the right pixel size. Computers \& geosciences, 32(9), 1283-1298. 